\title{
FERMENTASI JERAMI PADI UNTUK KOMPOS DENGAN BEBERAPA AKTIVATOR KOTORAN TERNAK DI DUSUN SUGIHAN TUBAN TAHUN 2016
}

\author{
Eliya Malika Oktavia, Darjati, Mamik
}

\begin{abstract}
Dusun Sugihan has thewidest area of paddy field in Desa Sumberejo with post-harvest rice straw of 12 tons/ha. Those rice straw have not used optimally.Ifleft untreated, it can spoil the aesthetics of the environment, generates odor and becomes a den of disease vectors.

The purpose of the present study was to determine the fermentation process of composts and the quality of composts produced with regard to temperature, humidity, $\mathrm{pH}$, water content, $\mathrm{C} / \mathrm{N}$ ratio and levels of $\mathrm{Pb}$ in composts.

The present study was a pre-experiment usinga statistical group comparison. Data were analyzed descriptively in order to describe the results of the field inspection and laboratory testing in accordance with SNI 19-7030-2004 on Compost Quality Standards.

Results of this 8-wk study showed that the fastest composting time was for the compost with chicken manure was the activator at a dose of 30\% for 3 weeks. In terms of compost quality, which includes temperature, pH, humidity, water content and levels of Pb,all of the composts fulfilled the requirements. However, with regard to $C / N$ ratio, those composts with activator of $10 \%$ cow manure, $10 \%$ goat manure and no manure did not fulfill the requirements with a $C / N$ ratio of $27.36,23.64$ and 26.75 , respectively.

Therefore, it is recommended to make composts using manure as an activatorat a dose $\geq 20 \%$ in order for fulfillment of $C / N$ ratio and shorter composting time.
\end{abstract}

Keywords: Compost fermentation, rice straw, manure as activator

\section{Pendahuluan}

Dusun Sugihan Desa Sumberejo mempunyai luas lahan sawah terluas di Desa Sumberejo yaitu 136,03 ha dan luas tanam 588 ha dengan hasil panen permusim yaitu 3311,6 ton. Jerami padi yang dihasilkan usai pemanenan sawah di Dusun Sugihan adalah kurang lebih 12 ton/ha, Selain itu sebagian warga di Dusun Sugihan juga memelihara hewan ternak seperti sapi, kambing dan ayam. Peternak sapi di dusun sugihan ada 45 orang dengan masing-masing peternak memiliki rata-rata 2-4 ekor sapi hingga lebih, peternak kambing di Dusun Sugiahan sebanyak 60 orang dengan masingmasing peternak kambing memiiki 3-10 kambing dan peternak ayam potong sebanyak 3 orang dengan masing-masing peternak memiliki ayam potong sebanyak 30.000-45.000 ekor ayam potong. Limbah Jerami padi dan kotoran ternak yang belum dimanfaatkan jika dibiarkan akan mengganggu estetika lingkungan, dapat menimmbulkan bau tidak sedap dan menjadi sarang vektor yang dapat menimbulkan penyakit.

\section{Tujuan Penelitian}

Untuk mengetahui proses fermentasi jerami padi dan kualitas kompos yang dihasilkan dengan menggunakan beberapa jenis aktivator kotoran ternak dengan dosis yang berbeda.

\section{Metode Penelitian}

Penelitian ini ditinjau dari jenisnya merupakan pra eksperimen yaitu static Group Comparison. Penelitian ini dilakukan pada bulan Februari sampai dengan Maret tahun 2016. Lokasi penelitian dilakukan di Dusun Sugihan Desa Sumberejo Tuban. Obyek penelitian ini adalah sampah organik yang berupa jerami padi kemudian masing-masing jerami padi ditambahkan beberapa aktivator kotoran ternak yaitu kotoran sapi, kotoran kambing, dan kotoran ayam dengan dosis aktivator masingmasing (10\%, 20\% dan 30\% dari jerami padi). Teknik pengumpulan data dengan pengukuran di lapangan dan hasil uji laboratorium. Penelitian ini dianalisa secara deskriptif yaitu menggambarkan hasil pemeriksaan/ uji laboratorium kemudian di bandingkan dengan standar yang sudah ada SNI 19-7030-2004 Tentang Standar Kualitas Kompos.

\section{Hasil Penelitian}

Hasil penelitian ini dapat dari pengukuran selama proses fermentasi kompos dengan bahan baku jerami padi dan aktivator kotoran ternak yang meliputi kontrol (KO), kompos dengan aktivator kotoran sapi dosis $10 \%$ (S1), kompos dengan aktivator kotoran sapi dosis $20 \%$ (S2), kompos dengan aktivator kotoran sapi dosis 30\% (S3), kompos dengan aktivator kotoran kambing dosis $10 \%$ (K1), kompos dengan aktivator kotoran kambing dosis $20 \%$ (K2), kompos dengan aktivator kotoran kambing dosis 30\% (K3), kompos dengan 
aktivator kotoran ayam dosis $10 \%$ (A1), kompos dengan aktivator kotoran ayam dosis 20\% (A2),

\section{Perubahan Fisik Kompos}

Berdasarkan hasil pengamatan kompos matang ditandai dengan perubahan fisik kompos seperti berwarna coklat gelap sampai hitam, berbau menyerupai tanah , tekstur lunak, dan terdapat gas dan kompos dengan aktivator kotoran ayam dosis $30 \%$ (A3). Berikut rincian hasil :

Pengukuran Di Lapangan : Berat awal dan berat akhir kompos

Tabel 1

Pengukuran Bahan dan Aktivator Kompos

\begin{tabular}{ccccccc}
\hline No. & Kode & $\begin{array}{c}\text { Berat Jerami } \\
(\mathrm{Kg})\end{array}$ & $\begin{array}{c}\text { Berat } \\
\text { Aktivator }(\mathrm{Kg})\end{array}$ & $\begin{array}{c}\text { Berat Awal } \\
(\mathrm{Kg})\end{array}$ & $\begin{array}{c}\text { Berat Akhir } \\
(\mathrm{Kg})\end{array}$ & $\begin{array}{c}\text { Penyusutan Kompos } \\
(\mathrm{Kg})\end{array}$ \\
\hline 1. & $\mathrm{~K} 0$ & 10 & - & 10 & 8 & $2(20 \%)$ \\
\hline 2. & $\mathrm{~S} 1$ & 10 & 1 & 11 & 8 & $3(30 \%)$ \\
\hline 3. & $\mathrm{~S} 2$ & 10 & 2 & 12 & 9 & $3(30 \%)$ \\
\hline 4. & $\mathrm{~S} 3$ & 10 & 3 & 13 & 10 & $3(30 \%)$ \\
\hline 5. & $\mathrm{~K} 1$ & 10 & 1 & 11 & 8 & $3(30 \%)$ \\
\hline 6. & $\mathrm{~K} 2$ & 10 & 2 & 12 & 9 & $3(30 \%)$ \\
\hline 7. & $\mathrm{~K} 3$ & 10 & 3 & 13 & 10 & $3(30 \%)$ \\
\hline 8. & $\mathrm{~A} 1$ & 10 & 1 & 11 & 8 & $3(30 \%)$ \\
\hline 9. & $\mathrm{~A} 2$ & 10 & 2 & 12 & 9 & $3(30 \%)$ \\
\hline 10. & $\mathrm{~A} 3$ & 10 & 3 & 13 & 10 & $3(30 \%)$ \\
\hline
\end{tabular}

Pengukuran Di lapangan : Suhu, Kelembaban Dan Ph Kompos Dan Waktu Pengomposan

Tabel 2

Pengukuran Suhu, Kelembaban dan pH Kompos

\begin{tabular}{cccccc}
\hline No. & Kode & $\begin{array}{c}\text { Rata-Rata Suhu } \\
\left({ }^{0} \mathrm{C}\right)\end{array}$ & $\begin{array}{c}\text { Rata-Rata Kelembaban } \\
(\%)\end{array}$ & $\begin{array}{c}\text { Rata-Rata } \\
\mathrm{pH}\end{array}$ & $\begin{array}{c}\text { Waktu } \\
(\text { Minggu })\end{array}$ \\
\hline 1. & K0 & 38,8 & 32,1 & 7 & 8 \\
\hline 2. & S1 & 40,3 & 33,5 & 7 & 6 \\
\hline 3. & S2 & 41,6 & 33,8 & 7 & 5 \\
\hline 4. & S3 & 40,7 & 34,3 & 7 & 4 \\
\hline 5. & K1 & 39,1 & 32,3 & 7 & 8 \\
\hline 6. & K2 & 40,5 & 32,2 & 7 & 5 \\
\hline 7. & K3 & 41,2 & 32,2 & 7 & 5 \\
\hline 8. & A1 & 39,2 & 32,4 & 7 & 4 \\
\hline 9. & A2 & 41,3 & 33,8 & 7 & 2 \\
\hline 10. & A3 & 41,7 & 33,7 & & 5 \\
\hline
\end{tabular}

Pemeriksaan uji Laboratorium : C/N Rasio, kadar air, logam berat $\mathbf{P b}$.

Tabel 3

C/N Rasio Kompos, Kadar Air Kompos, Pb Pada Kompos

\begin{tabular}{ccccccc}
\hline No. & Kode & $\mathrm{C}(\%)$ & $\mathrm{N}(\%)$ & $\mathrm{C} / \mathrm{N}$ Ratio $(\%)$ & Kadar Air (\%) & Logam berat Pb $(\mathrm{ppm})$ \\
\hline 1. & $\mathrm{~K} 0$ & 14,18 & 0,53 & 26,75 & 31,58 & 0,31 \\
\hline 2. & $\mathrm{~S} 1$ & 19,70 & 0,72 & 27,36 & 34,11 & 0,51 \\
\hline 3. & $\mathrm{~S} 2$ & 20,02 & 1,12 & 16,68 & 36,05 & 0,62 \\
\hline 4. & $\mathrm{~S} 3$ & 20,24 & 1,26 & 16,06 & 37,15 & 0,83 \\
\hline 5. & $\mathrm{~K} 1$ & 20,80 & 0,88 & 23,64 & 32,90 & 0,37 \\
\hline 6. & $\mathrm{~K} 2$ & 22,34 & 1,26 & 17,73 & 31,46 & 0,43 \\
\hline 7. & $\mathrm{~K} 3$ & 21,86 & 1,49 & 14,67 & 30,62 & 0,48 \\
\hline 8. & $\mathrm{~A} 1$ & 18,90 & 0,95 & 19,83 & 33,08 & 0,48 \\
\hline 9. & $\mathrm{~A} 2$ & 20,50 & 1,48 & 13,85 & 34,01 & 0,51 \\
\hline 10. & A3 & 21,60 & 1,76 & 12,27 & 33,70 & 0,66 \\
\hline
\end{tabular}


Tabel 4

Logam Berat Pada Bahan Baku Kompos

\begin{tabular}{clcc}
\hline No. & & Bahan & Logam Berat Pb (Ppm) \\
\hline 1. & Jerami padi & 0,37 \\
\hline 2. & Kotoran sapi & 0,96 \\
\hline 3. & Kotoran kambing & 0,42 \\
\hline 4. & Kotoran ayam & 1,18 \\
\hline
\end{tabular}

Dari hasil penelitian pada suhu kompos yang diukur dengan thermometer, rata-rata suhu awal kompos berkisar $29-35^{\circ} \mathrm{C}$ (tahap mesophilik), kemudian terjadi peningkatan suhu pada kisaran kurang dari $60^{\circ} \mathrm{C}$ (tahap termophilik), sedangkan pada akhir pengomposan suhu berkisar antara 28$30^{\circ} \mathrm{C}$ (tahap pendinginan) pada tahap ke tiga ini suhu mengalami penurunan sampai sama dengan suhu lingkungan. Dengan demikian suhu pengomposan sudah sesuai dengan tahap pengomposan.

Berdasarkan hasil pengamatan dilapangan tekstur kompos yang dihasilkan lebih lunak dan kandungan air lebih banyak hal ini sesuai dengan hasil pengukuran kelembaban pada awal pengomposan pada masing-masing kompos adalah $30 \%$, sedangkan pada akhir pengomposan kelembaban kompos berkisar antara 33-38\% yang berarti kelembaban mengalami kenaikan. Rata-rata kelembaban kelembaban kompos tertinggi adalah kompos dengan aktivator kotoran sapi dosis 30\% sebesar $34,3 \%$ dan rata-rata kelembaban kompos terendah adalah kompos tanpa aktivator (kontrol) sebesar $32,1 \%$. Hal ini berarti kelembaban pada saat pengomposan sudah sesuai dengan kelembaban optimum untuk pengomposan yaitu 3040 \%. (Subekti, Kurnia, 2015)

Kelembaban tertinggi ialah kompos dengan aktivator kotoran sapi dosis $30 \%$ di karenakan berdasarkan jurnal penelitian yang berjudul pupuk kandang kotoran sapi oleh Fitriana,Ap, 2012, kotoran sapi mengandung air lebih banyak dari pada kotoran kambing dan kotoran ayam.

Berdasarkan pengukuran $\mathrm{pH}$ kompos yang telah dilakukan dengan alat $\mathrm{pH}$ stik pada awal sampai akhir pengomposan adalah 7. Dengan demikian $\mathrm{Ph}$ sudah memenuhi syarat pengomposan berdasarkan SNI 19-7030-2004.

Dari hasil uji laboratorium, $\mathrm{C} / \mathrm{N}$ rasio kompos mencapai $12-27$, hal ini berarti terdapat $\mathrm{C} / \mathrm{N}$ rasio kompos yang belum sesuai SNI 19-7030-2004 tentang standar kualitas kompos, dimana syarat $\mathrm{C} / \mathrm{N}$ Rasio kompos adalah $<20$. kompos yang belum memiliki $\mathrm{C} / \mathrm{N}$ rasio $<20$ adalah kompos dengan aktivator kotoran sapi dosis $10 \%$ sebesar 27,36, kompos dengan aktivaror kotoran kambing dosis $10 \%$ sebesar 23,64 dan konmpos tanpa aktivator (kontrol) sebesar 26,75.

Untuk kompos tanpa aktivator (kontrol) dan kompos dengan aktivator kotoran sapi $10 \%$ dan kotoran kambing $10 \%$ kurang efektif untuk proses fermentasi kompos dalam penurunan $\mathrm{C} / \mathrm{N}$ rasio kompos. Hal ini dikarenakan tidak mencukupinya unsur nitrogen yang ada pada bahan baku dan aktivator kotoran sapi dan kotoran kambing dosis $10 \%$, dimana nitrogen adalah zat yang dibutuhkan bakteri penghancur untuk tumbuh dan berkembang biak. Selain penambahan dosis kotoran ternak, untuk meningkatkan unsur nitrogen pada kompos dapat dilakukan dengan penambahan waktu lebih lama dalam proses pengomposan karena berdasarkan jurnal dengan judul Pengaruh Waktu Pengomposan Terhadap Rasio Unsur C/N Dan Jumlah Kadar Air di dapatkan hasil yaitu semakin lama proses pengomposan maka unsur nitrogen dalam kompos semakin meningkat.

Dari hasil pengukuran kadar air pada kompos berkisar antara 31-37\%. Kadar air terbesar untuk kompos dengan aktivator kotoran sapi adalah kompos dengan dosis aktivator kotoran sapi dosis $30 \%$ sebesar $37,15 \%$, Kadar air terbesar untuk kompos dengan aktivator kotoran kambing adalah kompos dengan dosis aktivator kotoran kambing dosis $10 \%$ sebesar 32,90\%, Kadar air terbesar untuk kompos dengan aktivator kotoran ayam adalah kompos dengan dosis aktivator kotoran ayam dosis $20 \%$ sebesar $34,01 \%$. Hal ini sudah sesuai dengan SNI-19-7030-2004 untuk batas maksimum persen kadar air adalah $50 \%$. Berdasarkan hasil uji laboratorium untuk kadar air kompos tertinggi adalah kompos dengan aktivator kotoran sapi dosis $30 \%$ sebesar $37,15 \%$ dan kadar air terendah adalah kompos dengan aktivator kotoran kambing dosis 30\% sebesar 30,62\%.

Hal ini dimungkinkan kadar air dipengaruhi oleh jenis kotoran ternak dan dosis kotoran ternak dimana berdasarkan penelitian Fitriana, Ap, 2012 yang berjudul pupuk kandang, kadar air kotoran sapi lebih tinggi dari kadar air pada Kadar air kotoran kambing yaitu $80 \%$, kadar air kotoran kambing lebih tinggi sedikit dari kadar air kotoran ayam yaitu $64 \%$, sedangkan kadar air kotoran ayam relatif lebih rendah yaitu $57 \%$.

Berdasarkan hasil uji laboratorium logam berat $\mathrm{Pb}$ pada kompos, diperoleh hasil bahwa terdapat logam berat $\mathrm{Pb}$ pada jerami padi sebesar 0,37 Ppm. Logam berat yang ada pada jerami padi sebagian besar berasal dari tanah dan penggunaan beberapa jenis pupuk pada suatu lahan pertanian.

Selain pada jerami padi, logam berat $\mathrm{Pb}$ juga terdapat pada aktivator kotoran ternak yaitu kotoran sapi sebesar 0,96 ppm, logam berat pada kotoran kambing sebesar 0,42 ppm dan logam berat $\mathrm{Pb}$ pada kotoran ayam sebesar 1,18 ppm. 
Kotoran ternak yang mengandung logam berat salah satunya bisa berasal dari pakan ternak seperti konsentrat, dedak padi, jagung digiling, dan lainlain. Hal ini sesuai dengan jurnal dengan judul Deteksi Logam Zn, Cu, Pb dan Cd Pada Fases Sapi Potong dan Sesudah Proses Pembentukan Biogas Pada Digester Fixed Dome oleh raden Rizka Setyawati, dkk tahu 2015, kandungan logam berat pada fases sapi berkisar 38,69 ppm. Darmono (1995) menyatakan bahwa $\mathrm{Pb}$ dapat diserap melalui saluran pencernaan maupun saluran pernapasan. Selanjutnya $\mathrm{Pb}$ di adsorpsi ke dalam tubuh kemudian di distribusikan ke dalam jaringan tubuh. $\mathrm{Pb}$ kemudian dieksresikan kembali melalui feses.

Berdasarkan uji laboratorium pada Balai Penelitian Dan Konsultasi Industri (BPKI) logam berat $\mathrm{Pb}$ pada masing-masing kompos berkisar antara 0,31-0,83 ppm. Dengan logam berat terbesar pada kompos dengan aktivator kotoran sapi sebesar 0,83 ppm, dan logam berat $\mathrm{Pb}$ terkecil yaitu pada kontrol sebesar $0,31 \mathrm{ppm}$. Hal ini berarti terjadi penurunan logam berat jerami padi untuk kompos dengan aktivator kotoran ternak, dengan penurunan logam berat terbesar ada pada kompos jerami dengan aktivator kotoran sapi. Dimungkinkan yang berperan dalam menguraikan logam berat $\mathrm{Pb}$ adalah mikroba termophilik akibat dari panas yang dihasilkan pada suhu termophilik $\left(40-60^{\circ} \mathrm{C}\right)$

Dapat disimpulkan bahwa Berdasarkan SNI 19-7030-2004 tentang standar kualitas kompos, untuk logam berat pada kompos sudah memenuhi syarat pengomposan yaitu kurang dari $50 \mathrm{ppm}$.

Dari hasil penelitian ini waktu pengomposan tercepat adalah kompos dengan aktivator kotoran ayam dosis $30 \%$ yaitu selama 3 minggu, sedangkan untuk waktu pengomposan terlambat adalah kontrol (tanpa aktivator) dan kompos dengan aktivator kotoran kambing dosis $10 \%$ selama 8 minggu.

Pada penelitian ini waktu yang di butuhkan sekitar 21-56 hari. Hal ini sudah sesua berdasarkan teori pada Subekti Krisna (2015), untuk pembuatan kompos aerob memakan waktu selama 40-50 hari sedangkan anaerob memakan waktu selama 10-80 hari.

Pada kompos dengan ativator kotoran kambing dosis $10 \%$ memakan waktu yang sama dengan kompos tanpa aktivator (kontrol) sehingga kurang efektif dalam segi waktu pngomposan, perlu penambahan dosis aktivator agar kompos bisa matang lebih cepat.

Berdasarkan hasil penelitan, berat penyusutan kompos terkecil adalah pada kompos (tanpa aktivator) yaitu $20 \%$ sebesar $2 \mathrm{~kg}$ dari berat awal kompos yaitu $10 \mathrm{~kg}$, sedangkan berat penyusutan kompos dengan aktivator kotoran sapi, kotoran kambing, kotoran ayam dengan dosis $10 \%$, $20 \%$, dan $30 \%$ adalah $30 \%$ sebesar $3 \mathrm{~kg}$. Hal ini berarti penyusutan kompos sudah optimum.
Berat penyusutan kompos tanpa aktivator (kontrol) lebih sedikit dari kompos dengan aktivator yaitu sebesar 20\%, karena aktivator merupakan tambahan nutrisi pada bakteri untuk merombak bahan awal sehingga proses pengomposan bisa berjalan lebih cepat dan proses penyusutan kompos lebih banyak di bandingkan dengan kompos tanpa aktivator yang hanya memperoleh sumber nutrisi dari bahan baku kompos.

\section{Kesimpulan}

1. Suhu kompos sudah memenuhi syarat sesuai tahapan pengomposan yaitu $29-35^{\circ} \mathrm{C}$ (tahap meshopilik) kurang dari $60^{\circ} \mathrm{C}$ (tahap termophilik) dan tahap ke tiga antara $28-30^{\circ} \mathrm{C}$ (tahap pendinginan)

2. Kelembaban kompos sudah memenuhi syarat untuk kompos sebesar 30-38\% dengan ratarata kelembaban kompos sebesar 32,1\%$34,3 \%$.

3. $\mathrm{pH}$ kompos sudah memenuhi syarat untuk kompos sesuai SNI 19-7030-2004 tentang standar kualitas kompos yaitu 6,8-7,49.

4. Terdapat $\mathrm{C} / \mathrm{N}$ rasio kompos yang belum memenuhi syarat pengomposan sesuai SNI 19-7030-2004 tentang standar kualitas kompos yaitu kompos dengan aktivator kotoran sapi dosis $10 \%$ sebesar 27,36, kompos dengan aktivaror kotoran kambing dosis $10 \%$ sebesar 23,64 dan konmpos tanpa aktivator (kontrol) sebesar 26,75.

5. Kadar air kompos sudah memenuhi syarat untuk kompos yaitu 31-37\%.

6. Logam berat pada kompos sudah memenuhi syarat sesuai SNI 19-7030-2004 yaitu berkisar antara 0,31-0,36 ppm.

7. Waktu pengomposan tercepat adalah kompos dengan aktivator kotoran ayam dosis 30\% yaitu selama 3 minggu, sedangkan untuk waktu pengomposan terlambat adalah kontrol dan kompos dengan aktivator kotoran kambing dosis $10 \%$.

\section{Saran}

1. Masyarakat Dusun Sugihan : Disarankan dapat lebih memanfaatkan limbah jerami padi dan kotoran ternak sebagai kompos sehingga limbah tersebut tidak menjadi sampah dan hasilnya bisa di gunakan untuk pertanian.

2. Dinas Pertanian :

Disarankan dalam upaya pengolahan limbah hasil pertanian khususnya jerami padi adalah digunakan untuk kompos, dan untuk mempersingkat waktu membuat kompos bisa ditambahkan aktivator salah satunya yaitu kotoran ternak.

Penelitian yang akan datang disarankan memakai dosis aktivator $\geq 20 \%$ dari bahan baku agar waktu pengomposan lebih singkat dan $\mathrm{C} / \mathrm{N}$ rasio kompos sesuai syarat pengomposan. 


\section{DAFTAR PUSTAKA}

Ap,

Fitriana,

2011.

Pupuk

Kandang.http://www.academia.edu/84 46898 //PUPUK KANDANG.com. 21 Desember 2016

Harapah, R.T., T.Sabrian, and Marbun, P., 2015. Penggunaan Beberapa Sumber Dosis Aktivator Organik Untuk Meningkatkan Laju Dekomposisi Kompos Tandan Kosong Kelapa Sawit. Jurnal Online Agroekoteaknologi ISSN No.2337-6597. Edisi 2: (vol.3), 581.

Kusuma, Maria Erviana, 2012. Pengaruh Beberapa Jenis Pupuk Kandang Terhadap Kualitas Bokhasi. Jurnal Ilmu Hewani Tropika ISSN 2301-7783. Edisi 2 (Vol.1), 41.

Notoatmodjo, Soekidjo, 2010. Metodologi Penelitian Kesehatan. Jakarta:Rineka Cipta.
Setyawati, Raden Rizka, Harlia, Ellin, Juanda, Wowon, 2015. Deteksi Logam Zn, Cu, Pb Dan Cd Pada Feses Sapi Potong Sebelum

Dan Sesudah Proses Pembentukan Biogas Pada Digester Fixed-Dome. Fakultas peternakan Univeritas Padjajaran. .10 Juni 2016

SNI 19-7030-2004 tentang Standar Kualitas Kompos Subali, Bambang, Elianawati, 2016. Pengaruh Waktu Pengomposan Terhadap Rasio Unsur C/N Dan Jumlah Kadar Air Dalam Kompos. FMIPA UNNES Sekaran Gunungpati. 10 Juni 2016

Subekti, Krisna, 2015. Pembuatan Kompos Dari Kotoran Sapi (Komposting). http://www.academia.edu/10153713. Jurusan Teknik Pertanian Fakultas Teknologi Pertanian UGM Yogyakarta. 21 Desember 2015 